\title{
Inequality in uptake of isoniazid prevention therapy and Mantoux test among pregnant women with HIV in the Eastern Cape, South Africa
}

Oladele Vincent Adeniyi ${ }^{1 *}$, Nonkosi Selanto-Chairman², Eyitayo Omolara Owolabi ${ }^{3}$, Anthony Idowu Ajayi ${ }^{4,9^{*}}$ (D), Dominique Kabengele Kayembe ${ }^{5}$, Daniel Ter Goon ${ }^{6}$, Avramovic Gordana ${ }^{7}$ and John Lambert ${ }^{8}$

\begin{abstract}
Background: HIV-associated tuberculosis (TB) is a major cause of death among pregnant women in South Africa. Isoniazid prevention therapy (IPT) strategy was implemented in South Africa concurrently with life-long antiretroviral therapy (ART) to reduce the TB-associated morbidity and mortality in individuals living with HIV. This study assessed the extent of the implementation of IPT and the performance of the Mantoux test by geographic settings of health facilities and residences of pregnant women living with HIV in the Eastern Cape, South Africa.

Methods: We conducted a data analysis of 1709 pregnant women enrolled in the new electronic database of the prevention of mother-to-child transmission programme of the East London Prospective Cohort Study. Relevant data on place of residence and antenatal care, performance of the Mantoux test and subsequent initiation of IPT were obtained. Descriptive and inferential statistics were employed to analyse the geographical variations and accessibility to Mantoux test and IPT.

Results: The analysis shows that Mantoux test was performed on 803 pregnant women (47\%) with significant geographical variation. After controlling for relevant covariates, pregnant women who resided in rural areas (AOR:0.63; Cl: 0.47-0.84) compared to those who resided in urban areas were significantly less likely to receive Mantoux test. The rate of uptake of IPT was 79\% with significant geographic variations. In the unadjusted model, rural place of residence (UOR:0.68; Cl: 0.49-0.96) was independently associated with lower likelihood of uptake of INH prophylaxis; however, the effect was not significant after controlling for important covariates.

Conclusions: The high uptake rate of isoniazid prevention therapy in pregnant women living with HIV at the study sites is commendable; however, concerted efforts are needed to address the inequality gaps in the rollout of IPT. Poor performance of Mantoux test is a serious concern and requires the attention of TB programme managers and other relevant authorities.
\end{abstract}

Keywords: HIV-associated tuberculosis, Isoniazid prevention therapy, Mantoux test, Maternal mortality, Tuberculosisassociated morbidity, Tuberculosis-associated mortality

\footnotetext{
*Correspondence: vincoladele@gmail.com; ajayianthony@gmail.com; aiajayi@ufh.ac.za

${ }^{1}$ Department of Family Medicine \& Rural Health, Faculty of Health Sciences,

Walter Sisulu University, Mthatha/East London Hospital Complex, Cecilia

Makiwane Hospital, East London, South Africa

${ }^{4}$ Department of Sociology, Faculty of Social Sciences \& Humanities, University

of Fort Hare, East London, South Africa

Full list of author information is available at the end of the article
}

C The Author(s). 2019 Open Access This article is distributed under the terms of the Creative Commons Attribution 4.0 International License (http://creativecommons.org/licenses/by/4.0/), which permits unrestricted use, distribution, and reproduction in any medium, provided you give appropriate credit to the original author(s) and the source, provide a link to the Creative Commons license, and indicate if changes were made. The Creative Commons Public Domain Dedication waiver (http://creativecommons.org/publicdomain/zero/1.0/) applies to the data made available in this article, unless otherwise stated. 


\section{Background}

South Africa has the highest global burden of HIV and tuberculosis (TB) epidemic globally, with more than 300, 000 TB cases notified annually [1]. Since high HIV infection drives the growing burden of TB (epidemiological and biological link), South Africa is confronted with a huge burden of HIV and TB co-infection, especially among women [2]. With over seven million people living with HIV, and a prevalence of $30.2 \%$ among pregnant women in South Africa, with TB/HIV co-infection rate of $57 \%$, there is a definite cause for public health concern. The prevalence of TB in HIV-infected pregnant women is similar to the general population, approximately 795/100,000 [2]. TB is the leading cause of maternal mortality in South Africa; accounting for 26.2\% in non-pregnancy related infections [3]. The Eastern Cape Province has the second highest rate of TB cases, after Kwazulu-Natal, and is one of the three provinces lagging behind in the battle against TB and HIV in South Africa; others being the Northern Cape and North West Provinces [4].

Emerging evidence has shown that women of childbearing age are particularly susceptible to TB during pregnancy and this contributes significantly to the burden of maternal morbidity and mortality $[2,5,6]$. Besides, TB increases the risk of HIV transmission from the mother to the unborn child, abortion, premature delivery, post-partum haemorrhage, and pre-eclampsia $[7,8]$. Various immunological changes increase the risk of progressing from latent TB infection to active TB disease among pregnant women [9]. This risk is particularly higher among HIV-infected pregnant women, a rate ten times higher than that found among non-HIV-infected pregnant women [5] and this has made the prevention of TB among HIV-infected pregnant women a global priority. Also, there is a significant risk of adverse infant outcomes such as low birth weight, prematurity and overall infant mortality [6,10-12].

Combined antiretroviral therapy (ART) has been shown to reduce the risk of TB in HIV-infected individuals, including pregnant women; however, the incidence rate is still higher than acceptable levels. As such, the use of ART only is considered insufficient [13-16]. In the light of this, the Isoniazid Prevention Therapy (IPT) was introduced to augment ART. IPT is an essential public health strategy for prevention of TB among HIV infected individuals [17]. The IPT, with or without ART, has been shown in various randomised controlled trials and Cochrane reviews to significantly reduce the risk of developing active TB among those living with HIV who have latent TB infection [18-22]; with a 70 to $90 \%$ reduction. Studies in South Africa have also documented the effectiveness and safety of IPT, even among pregnant women and children [23, 24]. However, recent report by Gupta et al. [25] highlighted concerns of hepatotoxicity and adverse fetal outcomes following initiation of INH in pregnant and post-partum women on concomitant ART.

Globally, an increase in the uptake of IPT is recorded, however, the rate of uptake is still below acceptable levels, especially in the resource-poor settings [26, 27]. The World Health Global TB Report for 2015 showed that only $2.5 \%$ individuals living with HIV received IPT [28]. Studies conducted in resource-limited settings in some parts of sub-Saharan Africa, specifically AddisAbaba, Ethiopia have also reported low rates of IPT uptake ranging from 32 to $34 \%$ [29, 30]. A report on the uptake of IPT in South Africa also highlighted a low level of IPT uptake [31]. In order for South Africa to reduce the incidence of TB from 9800 per million in 2010 to 1500 per million in 2050 and TB-associated mortality from 2180 per million in 2010 to 200 per million in 2050, IPT must be scaled up to $75 \%$ by 2035 [32]. Many other studies across Africa reported rates ranging from $54 \%$ in a health district of Zimbabwe [33] to $77 \%$ in an urban health centres of Kenya [34]. The recorded low uptakes, irrespective of the geographical settings, have been linked to patients' related factors such as nonadherence, non-disclosure of HIV serostatus and lack of social support $[35,36]$ and health care related factors such as the levels of knowledge of the health care providers, and facilities being out of stock, amongst others [33, 37].

In 2014, the South African National Department of Health implemented the World Health Organization (WHO) recommendation on IPT [38]; 36 months for HIV-infected adults/adolescents with positive Mantoux test results and 12 months for Mantoux test negative individuals including pregnant women. This strategy was integrated into the mainstream HIV care services which included the intensified TB symptom screening. All patients, including pregnant women, receive TB symptom screening at diagnosis of HIV, following which the Mantoux test is performed once active TB has been excluded. Patients return after $48-72 \mathrm{~h}$ for reading of the Mantoux test. Isoniazid $300 \mathrm{mg}$ is prescribed by the attending clinician on the treatment sheet. The duration of IPT is documented in the medical records of each patient.

Since the introduction of the IPT guideline [38], there has been no published data on the current rate of implementation of IPT and the performance of the Mantoux test (a form of tuberculin skin test) in the Eastern Cape, and especially, among pregnant women in South Africa. We aimed to assess the current uptake of IPT by geographic settings of health facilities and residences of pregnant women living with HIV in the Eastern Cape, South Africa. In addition, this study evaluated the performance of the Mantoux test as a measure of compliance with the 
IPT guideline. Findings of this study might help to identify the gaps in the implementation of IPT by programme managers and primary health care facilities and might inform the crafting of strategies to scale up the uptake of IPT in the region.

\section{Methods}

\section{Study design}

This is a sub-analysis of a larger study, the East London Prospective Cohort Study, previously published elsewhere [39], which focused on evaluating the maternal and infant outcomes of the prevention of mother-to-child transmission programme in the Eastern Cape, South Africa.

\section{Study setting}

The data was collected in three large hospitals, namely, the Frere, Cecilia Makiwane and Bisho hospitals, serving a combined population of about two million people of the central region of Eastern Cape Province, South Africa. Frere hospital is an urban tertiary hospital receiving patients from across the entire central region of the Eastern Cape. In addition, Cecilia Makiwane hospital is a semiurban regional hospital located in Mdantsane Township and provides both district and specialised care to patients from Buffalo City, Amathole and Chris Hani districts. Bisho hospital is a district hospital and receives patients from the neighbouring rural primary health care facilities.

\section{Study participants}

All the participants enrolled in the electronic database of the East London Prospective Cohort Study (ELPCS) $(N=1709)$ were included in this study. Participants were included in the study if they received HIV diagnosis before or during the index pregnancy and attended the study sites for delivery between first of September 2015 to 31st of May 2016. All eligible participants took part in the study. The electronic data sheet of the ELPCS consisted of five different components; socio-demographic characteristics, HIV and ART history, Tuberculosis screening and IPT eligibility, pregnancy history and foetal outcomes and prophylaxis. This sub-study focused solely on the implementation of the IPT guideline within the cohort of the pregnant women enrolled in the database. Participants answered a few questions on whether they received a tuberculin skin test (Mantoux test) at the clinic before or during the index pregnancy and also, whether or not they had returned within $48-72 \mathrm{~h}$ to read the results. Participants' medical records were also checked to confirm that the results of the Mantoux tests had been documented in the medical records. Treatment sheets in the patients' medical records were extracted to confirm whether isoniazid had been prescribed in the preceding 2 years, prior to the study. Additional data on the place of antenatal care, the place and type of residence were extracted from the medical records. The drainage antenatal clinics to each delivery facility were categorised according to their catchment areas. Places of residence and ante-natal care were categorised as rural, semi-urban or urban based on the South African Census [40].

\section{Ethical consideration}

We obtained ethical approval from the Walter Sisulu University Ethics Committee (Reference: 098/2014). Permission was granted by the Eastern Cape Department of Health as well as the clinical governance of the respective hospitals. Participants received an information sheet (written in English and IsiXhosa) detailing the purpose and process of the study. Participants, subsequently, signed a written informed consent demonstrating their willingness to participate in the study. Few participants under the age of 18 years gave assent for their voluntary participation in the study while their legal guardian gave written informed consent for the study. Each participant was assigned a unique identifier (code) to prevent double entry. In addition, participants' names and other linked identifiers were excluded from the database in compliance with the participants' rights to privacy and confidentiality of medical information.

\section{Data analysis}

Data were verified for accuracy by the field supervisor during the period of data collection; data were exported into the Statistical Package for Social Sciences version 24.0 (SPSS, Chicago, IL, USA). Simple, descriptive statistics (means and proportions) were used to describe the baseline characteristics of the participants. Rates of uptake of IPT and performance of the Mantoux test were presented in bar charts. The indicators of the performance of Mantoux test and IPT were evaluated in a univariate analysis. Adjusted and unadjusted logistic regression were used to examine inequality in uptake of uptake of IPT and performance of the Mantoux test.

\section{Results}

The mean age of participants was $29.63( \pm 6.2)$ years (range 14-47 years). The majority of them were single (69.5\%), had grade 7 to 12 level of education $(86.5 \%)$ and were unemployed (74.7\%). Almost half $(46.3 \%)$ of the participants resided in semi-urban locations while $34.2 \%$ of them resided in rural areas (Table 1). The majority of the participants knew their HIV status at booking (80.1\%), and of those who knew their status, $71.9 \%$ were already on the highly active antiretroviral therapy.

\section{Clinical characteristics of patients}

A majority of the patients were diagnosed with HIV before the index pregnancy and most of them were already on anti-retroviral therapy (Table 2). Likewise, most of 
Table 1 Baseline characteristics of the participants

\begin{tabular}{|c|c|c|}
\hline Variables $(N=1709)$ & Frequency (n) & Percentage (\%) \\
\hline \multicolumn{3}{|l|}{ Age (years) ${ }^{a}$} \\
\hline$\leq 19$ & 60 & 3.5 \\
\hline $20-24$ & 331 & 19.5 \\
\hline $25-29$ & 459 & 27.0 \\
\hline $30-34$ & 452 & 26.6 \\
\hline $35-39$ & 303 & 17.8 \\
\hline $40-47$ & 96 & 5.6 \\
\hline \multicolumn{3}{|l|}{ Marital Status } \\
\hline Married & 312 & 18.3 \\
\hline Single & 1187 & 69.5 \\
\hline Cohabiting & 186 & 10.9 \\
\hline Divorced & 24 & 1.4 \\
\hline \multicolumn{3}{|l|}{ Place of Residence } \\
\hline Rural & 585 & 34.2 \\
\hline Semi-urban & 792 & 46.3 \\
\hline Urban & 332 & 19.4 \\
\hline \multicolumn{3}{|l|}{ Educational level } \\
\hline No formal education & 5 & 0.3 \\
\hline Grade 1-6 & 115 & 6.7 \\
\hline Grade 7-12 & 1479 & 86.5 \\
\hline Tertiary & 110 & 6.4 \\
\hline \multicolumn{3}{|l|}{ Employment status } \\
\hline Unemployed & 1277 & 74.7 \\
\hline Employed & 432 & 25.3 \\
\hline
\end{tabular}

${ }^{\text {a Missing data on age }(n=8)}$

the respondents booked for antenatal care during the second trimester (71.9\%), and in WHO stage one $(87.8 \%)$.

\section{Performance of Mantoux test}

Overall, the Mantoux test was performed in slightly less than half of the pregnant women in the study (47.3\%; $n=774)$; with considerably fewer Mantoux tests being performed in the rural health facilities (10\%). Health facilities in the urban and semi-urban areas performed more Mantoux tests; 54.2 and $50.5 \%$, respectively (Table 3 ).

The results of adjusted and unadjusted logistic regression analyses are presented in Table 4 . In the unadjusted model, demographic characteristics (age, marital status, place of residence, employment status and level of education) as well as the HIV status at first antenatal booking were independently associated with uptake of Mantoux testing. Clinical characteristics (CD4 count, viral load and trimester at antenatal care booking) were not significantly associated with uptake of Mantoux testing. However, in the adjusted model after adjusting for confounding factor (study site), negative status at first antenatal booking, place
Table 2 Clinical characteristics of the participants

\begin{tabular}{|c|c|c|}
\hline Variables $(N=1709)$ & Frequency & Percent \\
\hline \multicolumn{3}{|l|}{ Trimester at booking } \\
\hline First & 210 & 12.3 \\
\hline Second & 1229 & 71.9 \\
\hline Third & 270 & 15.8 \\
\hline \multicolumn{3}{|c|}{ Status at first antenatal booking } \\
\hline Positive & 1382 & 80.9 \\
\hline Negative & 94 & 5.5 \\
\hline Unknown & 233 & 13.6 \\
\hline \multicolumn{3}{|l|}{ On HAART at Booking } \\
\hline Yes & 998 & 58.4 \\
\hline No & 711 & 41.6 \\
\hline \multicolumn{3}{|l|}{ WHO Clinical Stage } \\
\hline Stage I & 1500 & 87.8 \\
\hline Stage II & 189 & 11.1 \\
\hline Stage III & 16 & 0.9 \\
\hline Stage IV & 4 & 0.2 \\
\hline \multicolumn{3}{|l|}{ CD4 at booking } \\
\hline 500 and above & 478 & 28.0 \\
\hline $200-499$ & 733 & 42.9 \\
\hline Unknown & 279 & 16.3 \\
\hline Less than 200 & 219 & 12.8 \\
\hline \multicolumn{3}{|l|}{ Viral load at booking } \\
\hline Undetectable $(<50)$ & 636 & 37.2 \\
\hline Low viremia (50-999) & 185 & 10.8 \\
\hline Unknown & 654 & 38.3 \\
\hline High viremia ( $\geq 1000)$ & 234 & 13.7 \\
\hline
\end{tabular}

SD Standard deviation, HAART Highly active anti-retroviral therapy, WHO World Health Organization

of residence and educational status were significantly associated with uptake of Mantoux test. Study sites confounds with place of residence and was not included in the models. Individuals who had grade 1-6 level of education were $49 \%$ less likely to have received a Mantoux test compared to those who had a tertiary level of education. Also, individuals who resided in rural areas were $37 \%$ less likely to have received a Mantoux test compared to those who resided in urban areas. The relationship between employment status and uptake of Mantoux test was not statistically significant after controlling for marital status, age and HIV status at booking.

\section{Uptake of isoniazid prevention therapy}

The rate of uptake of IPT was 79\% $(n=1309)$. However, rural health facilities lagged behind facilities in semi-urban and urban centres; $65.4 \%$ versus $83.9 \%$ versus $81 \%$, respectively. Pregnant women living in rural communities were the least likely to commence INH prophylaxis in 
Table 3 Indicators of performance of the Mantoux test and IPT

\begin{tabular}{|c|c|c|c|}
\hline Variables & $\begin{array}{l}\text { Performed } \\
\text { n (\%) }\end{array}$ & $\begin{array}{l}\text { Not } \\
\text { Performed } \\
\mathrm{n}(\%)\end{array}$ & $p$-value \\
\hline \multicolumn{4}{|l|}{ Mantoux Test by study sites } \\
\hline Frere hospital $(n=608)$ & $363(59.7)$ & $245(40.3)$ & \multirow[t]{3}{*}{$<0.001$} \\
\hline $\begin{array}{l}\text { Cecilia Makiwane hospital }(n= \\
\text { 711) }\end{array}$ & $379(53.3)$ & $332(46.7)$ & \\
\hline Bisho hospital $(n=319)$ & $32(10.0)$ & $287(90.0)$ & \\
\hline \multicolumn{4}{|l|}{ Mantoux Test by type of residence } \\
\hline Rural $(n=564)$ & $220(39.0)$ & $344(61.0)$ & \multirow[t]{3}{*}{$<0.001$} \\
\hline Semi-urban $(n=755)$ & $381(50.5)$ & $374(49.5)$ & \\
\hline Urban $(n=319)$ & $173(54.2)$ & $146(45.8)$ & \\
\hline \multicolumn{4}{|l|}{ INH prophylaxis by study sites } \\
\hline Frere hospital $(n=631)$ & $511(81.0)$ & $120(19.0)$ & \multirow[t]{3}{*}{$<0.001$} \\
\hline $\mathrm{CMH}(n=706)$ & $592(83.8)$ & $117(16.2)$ & \\
\hline Bisho $(n=315)$ & $206(65.4)$ & $109(34.6)$ & \\
\hline \multicolumn{4}{|l|}{ INH Prophylaxis by type of residence } \\
\hline Rural $(n=568)$ & $424(74.6)$ & $144(25.4)$ & \multirow[t]{3}{*}{0.004} \\
\hline Semi-urban $(n=760)$ & $622(81.8)$ & $138(18.8)$ & \\
\hline Urban $(n=324)$ & $263(81.2)$ & $61(18.8)$ & \\
\hline
\end{tabular}

$\mathrm{INH}=$ Isoniazid; Missing data were excluded from the analysis (there were missing data for 71 participants on Mantoux test and 57 missing data on INH Prophylaxis)

comparison to those living in semi-urban or urban centres; $74.6 \%$ versus $81.8 \%$ versus $81.2 \%$, respectively.

The results of the adjusted and unadjusted logistic regression analyses are presented in Table 5 . In the unadjusted model, the place of residence and employment status were independently associated with uptake of INH prophylaxis. However, after controlling for important covariates, the place of residence and employment were no longer significantly associated with INH prophylaxis. Study sites confounds with place of residence and was not included in the models.

\section{Discussion}

The present study sought to evaluate the uptake of isoniazid prevention therapy including the performance of the Mantoux test along rural-urban divide in the Eastern Cape, South Africa. Intensive symptom screening for active TB and performance of the Mantoux test in HIVinfected individuals without TB disease have been the core strategies implemented by the National Department of Health of South Africa [41] in order to mitigate the scourge of the TB epidemic. These strategies have the potential to further reduce the incidence of TB and TBassociated morbidity and mortality in people living with HIV. In view of the trends of TB-associated mortality in pregnant women living with HIV in South Africa [3], implementation of preventive measures has become imperative in the country, especially in the Eastern Cape. In the current study, the performance of the Mantoux test was low; only $47 \%$ of the eligible pregnant women had undergone the test. This is particularly concerning for pregnant women residing in the rural areas who accessed the rural health facilities. The performance of the Mantoux test was low in the rural health facilities where only $10 \%$ of the pregnant women living with HIV received the test.

Overall, the uptake of the Mantoux test is still below the acceptable level, however, the rates observed in the urban and semi-urban areas are encouraging, and thus, give optimism for improvement with better strategies. The wide disparity between the urban and rural dwellers should be a cause for concern for the TB programme managers and the Eastern Cape Health Department. As observed in this study, lower educational attainment and rural dwelling were associated with performance of Mantoux test. The result is not surprising in view of the fact that rural poor people tend to access the nearest health facilities to them. Although, variations in the performance of the Mantoux test could be expected across health facilities and geographic settings, the gap observed between rural and urban health facilities in this study brings to the fore the issues of inequality of access to quality healthcare services in the country. Rural health care facilities face numerous challenges with TB screening and diagnosis; inadequate human and financial resources [42] and long waiting periods due to overcrowding. The health care challenges of rural dwellers in the study area have been documented previously [43]. The rural dwellers are often very poor, thus, access to urban health care facilities are unattainable because of long distance of travel and prohibitive transport costs. In addition, regular stock out of the purified protein derivative (PPD) for the Mantoux test has been a major problem in the region, and rural health facilities are worst hit. Therefore, the findings of this study provide a dashboard for future references on the performance of the Mantoux test in the Eastern Cape. Also, the results of this study further corroborate the urgency for revitalisation and re-engineering of the primary health care in the region, with particular emphasis on prevention of diseases in the rural, poor communities.

Regardless of the result of the Mantoux test, a high uptake rate of IPT (79\%) was found in this study. This reinforces the optimism towards achieving the South African 2050 target of reducing the incidence and mortality due to TB; from 9800 per million in 2010 to 1500 per million in 2050 and 2180 per million in 2010 to 200 per million in 2050, respectively [32]. This rate is higher than the 34 and $32 \%$ uptake rate reported in some districts in Ethiopia [29, 30] and in Zimbabwe (54\%) [33]. However, a similar uptake rate was reported by Omesa et al. [34] in an urban health district of Ethiopia (77\%). 
Table 4 Adjusted and unadjusted logistic regression analysis showing socio-economic inequality in uptake of Mantoux Test

\begin{tabular}{|c|c|c|c|c|}
\hline Variables $(N=1638)$ & Never tested & Got tested & UOR & AOR \\
\hline \multicolumn{5}{|l|}{ Marital status } \\
\hline Single & $652(57.2)$ & $488(42.8)$ & $0.58(0.45-0.75)^{* * *}$ & $0.93(0.38-2.28)$ \\
\hline Cohabiting & $70(40.7)$ & $102(59.3)$ & $1.13(0.78-1.66)$ & $0.58(0.24-1.39)$ \\
\hline Divorce/separated & $9(40.9)$ & $13(59.3)$ & $1.12(0.47-2.71)$ & $0.97(0.39-1.19)$ \\
\hline Married & $133(43.8)$ & $171(56.3)$ & 1 & 1 \\
\hline \multicolumn{5}{|l|}{ Education status } \\
\hline No formal Education & $2(40.0)$ & $3(60.0)$ & $1.25(0.20-7.76)$ & $1.19(0.19-7.67)$ \\
\hline Grade 1-6 & $73(67.0)$ & $36(33.0)$ & $0.41(0.24-0.71)^{*}$ & $0.51(0.29-0.91)^{*}$ \\
\hline Grade 7-12 & $740(52.3)$ & $676(47.7)$ & $0.76(0.51-1.12)$ & $0.83(0.55-1.25)$ \\
\hline Tertiary & $49(45.4)$ & $59(54.6)$ & 1 & 1 \\
\hline \multicolumn{5}{|l|}{ Place of Residence } \\
\hline Rural & $344(61.0)$ & $220(39.0)$ & $0.54(0.41-0.71)^{* * *}$ & $0.63(0.47-0.84)^{*}$ \\
\hline Semi-urban & $374(49.5)$ & $381(50.5)$ & $0.86(0.66-1.12)$ & $0.91(0.69-1.19)$ \\
\hline Urban & $146(45.8)$ & $173(54.2)$ & 1 & 1 \\
\hline \multicolumn{5}{|l|}{ Employment status } \\
\hline Employed & $191(46.0)$ & $224(54.0)$ & $1.44(1.15-1.79)^{*}$ & $1.24(0.98-1.56)$ \\
\hline Unemployed & $673(55.0)$ & $550(45.0)$ & 1 & 1 \\
\hline \multicolumn{5}{|l|}{ Age } \\
\hline$\geq 25$ years & $640(51.0)$ & $616(49.0)$ & $1.33(1.05-1.68)^{*}$ & $1.26(0.99-1.62)$ \\
\hline$<25$ years & $218(58.0)$ & $158(42.0)$ & 1 & 1 \\
\hline \multicolumn{5}{|l|}{ HIV Status at booking } \\
\hline Positive & $722(54.2)$ & $610(45.8)$ & $0.86(0.65-1.15)$ & $0.85(0.63-1.15)$ \\
\hline Negative & $32(36.4)$ & $56(63.6)$ & $1.78(1.07-2.97)^{*}$ & $1.70(1.01-2.88)^{*}$ \\
\hline Unknown & $110(50.5)$ & $108(49.5)$ & 1 & 1 \\
\hline \multicolumn{5}{|l|}{ Trimester at booking } \\
\hline First & $83(48.3)$ & $89(51.7)$ & $1.15(0.78-1.69)$ & $1.13(0.76-1.68)$ \\
\hline Second & $644(53.6)$ & $557(46.4)$ & $0.93(0.71-1.21)$ & $1.02(0.77-1.34)$ \\
\hline Third & $137(53.6)$ & $128(48.3)$ & 1 & 1 \\
\hline \multicolumn{5}{|l|}{ CD4 at booking } \\
\hline 500 and above & $263(56.9)$ & $199(43.1)$ & $0.75(0.54-1.04)$ & $0.77(0.54-1.09)$ \\
\hline $200-499$ & $372(52.2)$ & $340(47.8)$ & $0.91(0.67-1.23)$ & $0.93(0.68-1.28)$ \\
\hline Unknown & $122(49.0)$ & $127(51.0)$ & $1.03(0.72-1.49)$ & $1.06(0.71-1.56)$ \\
\hline Less than 200 & $107(49.8)$ & $108(50.2)$ & 1 & 1 \\
\hline \multicolumn{5}{|l|}{ Viral load at booking } \\
\hline Undetectable $(<50)$ & $333(53.8)$ & $286(46.2)$ & $1.01(0.74-1.38)$ & $0.95(0.68-1.32)$ \\
\hline Low viremia (50-999) & $97(53.3)$ & $85(46.7)$ & $1.03(0.70-1.53)$ & $0.94(0.62-1.42)$ \\
\hline Unknown & $315(51.1)$ & $302(48.9)$ & $1.13(0.83-1.54)$ & $1.02(0.73-1.41)$ \\
\hline High viremia ( $\geq 1000)$ & $119(54.1)$ & $101(45.9)$ & 1 & 1 \\
\hline
\end{tabular}

*** $p$-value $<0.001 ;{ }^{*} p$-value < 0.005; UOR- Unadjusted Odds Ratio; AOR-Adjusted Odds Ratio

This shows an improvement in the uptake of IPT in this setting and this could help to further reduce the morbidity and mortality associated with TB among HIV-infected pregnant women. However, there is still room for scale up of IPT implementation for all individuals living with HIV in the entire region, irrespective of geographic settings.
While this study has provided a snapshot of the current situation of IPT implementation, periodic evaluation is imperative to ensure that poor performing health facilities can improve their service delivery to the community.

Though, this study found no association between the INH uptake and the HIV indicators in the logistic 
Table 5 Adjusted and unadjusted binary logistic regression models showing relationship between sociodemographic factors, clinical characteristics and uptake of INH Prophylaxis

\begin{tabular}{|c|c|c|c|c|}
\hline Variables $(N=1652)$ & Did not receive INH & Received INH & UOR & AOR \\
\hline \multicolumn{5}{|l|}{ Marital status } \\
\hline Single & $247(21.7)$ & $893(78.3)$ & $0.88(0.64-1.20)$ & $0.71(0.23-2.18)$ \\
\hline Cohabiting & $32(17.8)$ & $148(82.2)$ & $1.12(0.70-1.80)$ & $0.68(0.23-2.04)$ \\
\hline Divorce/separated & $4(16.7)$ & $20(83.3)$ & $1.21(0.40-3.67)$ & $0.80(0.25-2.53)$ \\
\hline Married & $60(19.5)$ & $248(80.5)$ & 1 & 1 \\
\hline \multicolumn{5}{|l|}{ Education status } \\
\hline No formal Education & $1(20.0)$ & $4(80.0)$ & $0.97(0.10-9.09)$ & $1.53(0.15-15.56)$ \\
\hline Grade 1-6 & $29(26.9)$ & $79(73.1)$ & $0.66(0.35-1.25)$ & $0.72(0.37-1.39)$ \\
\hline Grade 7-12 & $292(20.4)$ & $1139(79.6)$ & $0.94(0.58-1.54)$ & $1.01(0.61-1.68)$ \\
\hline Tertiary & $21(19.4)$ & 87 (80.6) & 1 & 1 \\
\hline \multicolumn{5}{|l|}{ Place of Residence } \\
\hline Rural & $144(25.4)$ & $424(74.6)$ & $0.68(0.49-0.96)^{*}$ & $0.72(0.51-1.02)$ \\
\hline Semi-urban & $138(18.2)$ & $622(81.8)$ & 1.05 0.75-1.46) & $1.07(0.76-1.50)$ \\
\hline Urban & $61(18.8)$ & $263(81.2)$ & 1 & 1 \\
\hline \multicolumn{5}{|l|}{ Employment status } \\
\hline Employed & $271(22.0)$ & $959(78.0)$ & $1.37(1.03-1.83)^{*}$ & $1.29(0.96-1.74)$ \\
\hline Unemployed & $72(17.1)$ & $350(82.9)$ & 1 & 1 \\
\hline \multicolumn{5}{|l|}{ Age } \\
\hline$\geq 25$ years & $80(21.2)$ & $297(78.8)$ & $1.03(0.78-1.37)$ & $0.94(0.70-1.27)$ \\
\hline$<25$ years & $263(20.7)$ & $1006(79.3)$ & 1 & 1 \\
\hline \multicolumn{5}{|l|}{ HIV Status at booking } \\
\hline Positive & $277(20.7)$ & $1062(79.3)$ & $1.04(0.74-1.47)$ & $1.03(0.72-1.48)$ \\
\hline Negative & $18(20.5)$ & $70(79.5)$ & $1.06(0.57-1.94)$ & $1.00(0.54-1.85)$ \\
\hline Unknown & $48(21.3)$ & $177(78.7)$ & 1 & 1 \\
\hline \multicolumn{5}{|l|}{ Trimester at booking } \\
\hline First & $51(28.2)$ & $130(71.8)$ & $0.65(0.42-1.01)$ & $0.66(0.42-1.03)$ \\
\hline Second & $238(19.7)$ & $968(80.3)$ & $1.04(0.75-1.45)$ & $1.07(0.77-1.51)$ \\
\hline Third & $54(20.4)$ & $211(79.6)$ & 1 & 1 \\
\hline \multicolumn{5}{|l|}{ CD4 at booking } \\
\hline 500 and above & $91(19.4)$ & $377(80.6)$ & $1.21(0.82-1.79)$ & $1.18(0.78-1.78)$ \\
\hline $200-499$ & $145(20.2)$ & $573(79.8)$ & $1.15(0.80-1.66)$ & $1.13(0.78-1.66)$ \\
\hline Unknown & $58(23.3)$ & $191(76.7)$ & $0.96(0.62-1.48)$ & $1.00(0.63-1.57)$ \\
\hline Less than 200 & 49 (22.6) & $168(77.4)$ & 1 & 1 \\
\hline \multicolumn{5}{|l|}{ Viral load at booking } \\
\hline Undetectable $(<50)$ & $112(17.8)$ & $517(82.2)$ & $1.41(0.97-2.03)$ & $1.30(0.88-1.92)$ \\
\hline Low viremia (50-999) & $47(25.7)$ & $136(74.3)$ & $0.88(0.56-1.39)$ & $0.80(0.50-1.27)$ \\
\hline Unknown & $131(21.3)$ & $482(78.6)$ & $1.12(0.78-1.61)$ & $1.11(0.76-1.63)$ \\
\hline High viremia $(\geq 1000)$ & $53(23.3)$ & $174(76.7)$ & 1 & 1 \\
\hline
\end{tabular}

***P-value $<0.001 ;{ }^{*} P$-value $<0.005 ;$ UOR- Unadjusted Odds Ratio; AOR-Adjusted Odds Ratio

regression models; WHO clinical stage, CD4 count at booking and viral load, the epidemiological and biological link between the two infections are well documented $[1-5,10]$. Given the rapid progression of latent to active TB during pregnancy [5], and its significant morbidity and mortality risks in HIV-infected pregnant women [1-4], this important preventive strategy should be accessible to all women living with HIV. However, clinicians initiating IPT in pregnant women should carefully monitor their patients for liver function adverse 
events, and grade 3 and above infant adverse events, given the report by Gupta et al. [25], which raised concerns on the safety of INH in this population.

Similar to the performance of the Mantoux tests, the uptake of IPT was higher in semi-urban and urban areas compared to rural areas. Though, the rural - urban disparity in the uptake of IPT was not statistically significant in the adjusted logistic regression model, the core issues around inequality in the quality of healthcare services across the socioeconomic divide cannot be ignored. The disparity between the performance of the Mantoux test and IPT initiation suggests that patients were initiated on the latter without the Mantoux test. HIV-infected pregnant women were more likely to be initiated on IPT without Mantoux test in the rural areas than in the urban areas. While this practice was supported by the directives of the South African National Department of Health during the period of stock out of PPD (Mantoux test) in the country, it was advised, however, that patients who received IPT should have the Mantoux test done as soon as it became available. It is however, commendable that pregnant women needing IPT might still receive the service in the rural health facilities regardless of Mantoux test. Hence, there is a good platform to begin health system strengthening in the rural communities of Eastern Cape. The rural health facilities more often than not, lack the resources (manpower and infrastructure) to adequately monitor and track patients to return for the Mantoux test. This challenge requires the attention of TB programme managers. There is an urgent need to scale up interventions to increase IPT uptake and ensure total coverage, particularly in the rural areas where access to quality healthcare is limited.

\section{Strengths and limitations}

The three large maternity centres with their wide drainage antenatal clinics representing various demographic and geographic settings within the region gave credence to the findings of the study. Although the study provides a snapshot of the current performance of the health facilities in the region, periodic monitoring of IPT and the Mantoux test can potentially provide information on the trends and add greater value, hence, is recommended for the attention of TB programme managers. Despite the fact that the study participants live in communities similar to the entire country, the findings may not be generalizable to the entire country.

\section{Conclusion}

The high uptake rate of isoniazid prevention therapy in pregnant women living with HIV in the study setting was commendable. However, the rate of performance of Mantoux test was generally low and worse in the rural health facilities. This study further highlights the inequality in the healthcare service delivery between rural and urban communities in the region. HIV-infected women with low educational attainment and residing in rural communities were less likely to have Mantoux test performed. Concerted efforts are needed to address the rural-urban inequality gaps in the roll-out of IPT and Mantoux test. TB programme managers should monitor both the Mantoux test and IPT rollout periodically with a view of reducing $\mathrm{TB}$ incidence and mortality in the region.

\section{Abbreviations \\ ART: antiretroviral therapy; ELPCS: East London Prospective Cohort Study; HIV: human immunodeficiency virus; INH: isoniazid; IPT: isoniazid prevention therapy; TB: tuberculosis; TST: tuberculin skin test \\ Acknowledgements \\ We express our gratitude to the entire management and staff of Frere, Cecilia Makiwane and Bisho Hospitals. We also appreciate the hard work of the Relevance Network Team; Craig Carty, Lulama Sidloyi, Shulie Majambe, Elizabeth Bosha, Sandi Mzilikazi, Prince Sofute and Sandile Mqwashini in implementing the project. The abstract of this paper was presented at the 37th Conference on priorities in perinatal care in Southern Africa.}

\section{Authors' contributions}

OVA, NSC, DTG, GA, JL and AIA conceptualised and designed the study. AIA conducted the data analysis. EOO, OVA, GA, JL and DKK drafted the manuscript. All authors gave intellectual input and approved the final version of the manuscript for submission.

\section{Funding}

OVA received research grants from the Association of African Universities, Stellenbosch University Collaborative Capacity Enhancement through Engagement with Districts (SUCCEED) and Discovery Foundation towards a PhD study, of which this paper is a part. The Positive Action Grant from ViiV Healthcare Limited granted to CC, JL \& OVA was used to develop the electronic database. The funders were not involved in the design and implementation of this study.

\section{Availability of data and materials}

All data are available from the corresponding authors upon reasonable requests.

\section{Ethics approval and consent to participate}

The Walter Sisulu University Ethics Committee approved the study. Participants gave written consent, and the study was conducted by respecting the right of participants to privacy, anonymity and confidentiality. Also, we obtained parental/legal consent for participants under 18 years old.

\section{Consent for publication}

Not applicable.

\section{Competing interests}

AIA is an associate editor at BMC Public Health. Other authors declared that they had no conflict of interests.

\footnotetext{
Author details

${ }^{1}$ Department of Family Medicine \& Rural Health, Faculty of Health Sciences, Walter Sisulu University, Mthatha/East London Hospital Complex, Cecilia Makiwane Hospital, East London, South Africa. ${ }^{2}$ Department of Public Health, Faculty of Health Sciences, University of Fort Hare, East London, South Africa. ${ }^{3}$ Department of Nursing Sciences, Faculty of Health Sciences, University of Fort Hare, East London, South Africa. ${ }^{4}$ Department of Sociology, Faculty of Social Sciences \& Humanities, University of Fort Hare, East London, South Africa. ${ }^{5}$ Department of Family Medicine \& Rural Health, Faculty of Health Sciences, Walter Sisulu University, Mthatha/East London Hospital Complex, Cecilia Makiwane Hospital, East London, South Africa. ${ }^{6}$ Department of
} 
Nursing Sciences, Faculty of Health Sciences, University of Fort Hare, East London, South Africa. ${ }^{7}$ Department of Infectious Diseases, Medicine and Sexual Health. Mater, Rotunda and University College, Dublin, Ireland. ${ }^{8}$ Department of Infectious Diseases, Medicine and Sexual Health. Mater, Rotunda and University College, Dublin, Ireland. ${ }^{9}$ Population Dynamics and Sexual and Reproductive Health Unit, African Population and Health Research Center, Nairobi, Kenya.

\section{Received: 3 January 2019 Accepted: 11 October 2019} Published online: 29 October 2019

\section{References}

1. WHO Department of HIV/AIDS, Stop TB Department. Guidelines for Intensified Tuberculosis Case-Finding and Isoniazid Preventive Therapy for People Living with HIV in Resource-Constrained Settings. Geneva: WHO; 2010. http://www.who.int/hiv/pub/tb/9789241500708/en/.

2. Martin CE, Black V. Tuberculosis prevention in HIV-infected pregnant women in South Africa. Southern African Journal of HIV Medicine. 2012;13(4):182-4.

3. National Committee on Confidential Enquiries into Maternal Deaths. Saving Mothers 2011-2013: Sixth report on confidential enquiries into maternal deaths in South Africa. Available on: http://www.kznhealth.gov.za/mcwh/ Maternal/Saving-Mothers-2011-2013-short-report.pdf.

4. Health Systems Trust. District Health Barometer 2013/14. Durban: HST [taken from ETR.DHIS], 2014.

5. Coutsoudis A, England K, Rollins N, Coovadia H, Newell M-L, Bland R. Women's morbidity and mortality in the first 2 years after delivery according to HIV status. AIDS. 2010;24(18):2859-66.

6. Zvandasara P, Hargrove JW, Ntozini R, Chidawanyika H, Mutasa K, lliff PJ, et al. Mortality and morbidity among postpartum HIV positive and HIV-negative women in Zimbabwe: risk factors, causes, and impact of single-dose postpartum vitamin a supplementation. J Acquir Immune Defic Syndr. 2006;43(1):107-16.

7. Desai M, Phillips-Howard PA, Odhiambo FO, Katana A, Ouma P, Hamel MJ, et al. An analysis of pregnancy-related mortality in the KEMRI/CDC health and demographic surveillance system in western Kenya. PLoS One. 2013;8:e68733.

8. Lathrop E, Jamieson DJ, Danel I. HIV and maternal mortality. Int J Gynaecol Obstet. 2014;127:213-5.

9. Bates M, Ahmed Y, Kapata N, Maeurer M, Mwabab P, Zumla A. Perspectives on tuberculosis in pregnancy. Int J Infect Dis. 2015;32:124-7.

10. Gupta A, Gupte N, Patil S, et al. Maternal TB is associated with increased risk of HIV mother-to-child transmission. Conference on Retroviruses and Opportunistic Infections. 2010. Abstract 899. Available from: http:// retroconference.org/2010/Abstracts/37899.htm.

11. Lin HC, Lin HC, Chen SF. Increased risk of low birthweight and small for gestational age infants among women with tuberculosis. BJOG. 2010;117:585-90.

12. Pillay T, Sturm AW, Khan M, Adhikari M, Moodley J, Connolly C, et al. Vertical transmission of mycobacterium tuberculosis in KwaZulu Natal: impact of HIV-1 co-infection. Int J Tuberc Lung Dis. 2004;8:59-69.

13. Durovni B, Solange C, Cavalcantea C, Saracenia V, Vellozoa V, Israela G. The implementation of isoniazid preventive therapy in HIV clinics: the experience from the TB/HIV in Rio (THRio). Study AIDS. 2010;24(Suppl 5):S49-56.

14. Santoro-Lopes G, de Pinho AM, Harrison LH, Schechter M. Reduced risk of tuberculosis among Brazilian patients with advanced human immunodeficiency virus infection treated with highly active antiretroviral therapy. Clin Infect Dis. 2002;34:543-6.

15. Jones JL, Hanson DL, Dworkin MS, DeCock KM. HIV-associated tuberculosis in the era of highly active antiretroviral therapy. The adult/adolescent spectrum of HIV disease group. Int T Tuberc Lung Dis. 2000;4(11):1026-31.

16. Girardi E, Antonucci G, Vanacore P, Libanore M, Errante I, Matteeli A, et al. Impact of combination antiretroviral therapy on the risk of tuberculosis among persons with HIV infection. AIDS. 2000;14:1985-91.

17. World Health Organisation. Global Tuberculosis Report, Geneva. 2017a. Available from: http://www.who.int/tb/publications/global_report/en/.

18. Semu M, Fenta TG, Medhin G, Assefa D. Effectiveness of isoniazid preventative therapy in reducing incidence of active tuberculosis among people living with HIV/AIDS in public health facilities of Addis Ababa, Ethiopia: a historical cohort study. BMC Infect Dis. 2017;17:5.

19. Smieja MJ, Marchetti CA, Cook DJ, Smaill FM. Isoniazid for preventing tuberculosis in non-HIV infected persons. Cochrane Database Syst Rev. 2000;2:CD001363.

20. Akolo C, Adetifa I, Shepperd S, Volmink J. Treatment of latent tuberculosis infection in HIV infected persons 2010. Available from: http://www2. cochrane.org/reviews/en/ab000171.html.
21. Zar HJ, Cotton MF, Strauss S, Karpakis J, Hussey G, Schaaf HS, et al. Effect of isoniazid prophylaxis on mortality and incidence of tuberculosis in children with HIV: randomised controlled trial. BMJ. 2007;334(7585):136.

22. Madhi SA, Nachman S, Violari A, Kim S, Cotton MF, Bobat R, et al. Primary isoniazid prophylaxis against tuberculosis in HIV-exposed children. N Engl J Med. 2011;365:21-31.

23. Bristow CC, Larson E, Vilakazi-Nhlapo AK, Wilson M, Klausner JD. Scale-up of isoniazid preventive therapy in PEPFAR-assisted clinical sites in South Africa. Int J Tuberc Lung Dis. 2012;16(8):1020-2.

24. Churchyard GJ, Chaisson RE, Maartens G, Getahun H. Tuberculosis preventive therapy: an underutilised strategy to reduce individual risk of TB and contribute to TB control. S Afr Med J. 2014;104(5):339-43.

25. Gupta A, Montepiedra G, Aaron L, Theron G, McCarthy K, OnyangoMakumbi C, Chipate T, Masheto G, Shin K, Zimmer B, Sterling TR. Randomized trial of safety of isoniazid preventive therapy during or after pregnancy. In25th Conference on Retroviruses and Opportunistic Infections (CROI 2018) 2018 Mar 4 (pp. 4-7).

26. World Health Organization. A guide to Monitoring and Evaluation for Collaborative TB/HIV Activities. Geneva: WHO; 2009. p. 26-7.

27. World Health Organization. Global tuberculosis control: a short update to the 2010 Report. Geneva, Switzerland 2010.

28. WHO. TB/HIV facts: challenges and key issues. Geneva. 2010. Available from: http://www.who.int/hiv/topics/tb/tbhiv_facts_2015/en/.

29. Yirdaw KD, Jerene D, Gashu Z, Edginton ME, Kumar AMV, et al. Beneficial effect of isoniazid preventive therapy and antiretroviral therapy on the incidence of tuberculosis in people living with HIV in Ethiopia. PLoS One. 2014;9(8):e104557.

30. Wesen A, Mitike G. Provision and awareness for isoniazid preventive therapy among PLHIV in Addis Ababa, Ethiopia. BMC Int Health Hum Rights. 2012;12:2.

31. Ndebele Nomatter. Time to scale up IPT uptake in South Africa. Spotlight, 2015. Available from: https://www.spotlightnsp.co.za/2015/10/22/time-toscale-up-ipt-in-south-africa/.

32. Dye C, Glaziou P, Floyd K, Raviglione M. Prospects for tuberculosis elimination. Annu Rev Public Health. 2013:34:271-86.

33. Makoni A, Chemhuru M, Tshimanga M, Gombe NT, Mungati M, Bangure D. Evaluation of the isoniazid preventive therapy (IPT) program in Shurugwi District, Midlands Province, Zimbabwe, January 2013 to august 2014. BMC Res Notes. 2015:8:476.

34. Omesa EN, Kathure IA, Masini E, Mulwa R, Maritim A, Owiti PO, et al. Uptake of isoniazid preventive therapy and its associated factors among HIV positive patients in an urban health Centre, Kenya. East Afr Med J. 2016;93(10):S47-54.

35. Mindachew M, Deribew A, Memiah P, Biadgilign S. Perceived barriers to the implementation of isoniazid preventive therapy for people living with HIV in resource constrained settings: a qualitative study. Pan Afr Med J. 2014;17:26.

36. Nyamathi AMCA, Nahid P, Gregerson P, Leake B. A randomized controlled trial of two treatment programs for homeless adults with latent tuberculosis infection. Int J Tuberc Lung Dis. 2006;7(10):775-82.

37. Szakacs TA, Wilson D, Cameron DW, Clark M, Kocheleff P, Muller FJ, et al. Adherence with isoniazid for prevention of tuberculosis among HIV-infected adults in South Africa. BMC Infect Dis. 2006;13;6:97.

38. South African anti-retroviral treatment guidelines. Available from: http:// www.kznhealth.gov.za/medicine/2013_art_guidelines.pdf.

39. Adeniyi OV, Ajayi Al, Selanto-Chairman N, Goon DT, Boon G, Fuentes YO, et al. Demographic, clinical and behavioural determinants of HIV serostatus non-disclosure to sex partners among HIV-infected pregnant women in eastern cape, South Africa. PLoS One. 2017;12(8):e0181730.

40. Statistics South Africa. Census 2001: Investigation into appropriate definitions of urban and rural areas of South Africa; Discussion document. Available from: http://www.statssa.gov.za/census/census_2001/urban_rural/urbanrural.pdf.

41. National Department of Health. Joint Review of HIV, TB and PMTCT Programmes in South Africa. Pretoria: Department of Health; 2014.

42. World Health Organisation. Factsheet on Tuberculosis. Available from: http://www.who.int/mediacentre/factsheets/fs104/en/.

43. Adeniyi OV, Yogeswaran P, Wright G, Longo-Mbenza B. Diabetic patients' perspectives on the challenges of glycaemic control. African journal of primary health care \& family medicine. 2015;7(1):1-8.

\section{Publisher's Note}

Springer Nature remains neutral with regard to jurisdictional claims in published maps and institutional affiliations. 